\title{
Management of Teeth with Necrotic Pulp and Open Apices - Clinical Practice Guideline
}

\author{
Jerry Jose ${ }^{1}$, Ajitha $\mathrm{P}^{2}$ and Subash Sharma ${ }^{3}$ \\ ${ }^{1}$ Post Graduate Student, Department of Conservative Dentistry and Endodontics, Saveetha Dental \\ College, Saveetha Institute of Medical and Technical Sciences, Saveetha University, Chennai, India. \\ ${ }^{2}$ Professor, Department of Conservative Dentistry and Endodontics, Saveetha Dental College, Saveetha \\ Institute of Medical and Technical Sciences, Saveetha University, Chennai, India. \\ ${ }^{3}$ Reader, Department of Conservative Dentistry and Endodontics Saveetha Dental College, \\ Saveetha Institute of Medical And Technical Sciences, Saveetha University, Chennai, India.
}

\begin{abstract}
The endodontic treatment of permanent teeth with open apices and necrotic pulp is considered one of the most complex challenges for clinicians. Tooth with open apices show thin radicular walls have increased susceptibility to fracture, the wide lumen of the apical foramen makes it difficult to maintain the filling material inside the root canals and Difficult for proper cleaning mechanically. In order to avoid excessive root weakness the treatment of such cases depends on various factors and is a multifactorial process. This study aims to formulate certain guidelines which the clinician can follow in such case scenarios to best provide a treatment outcome for such case scenarios.
\end{abstract}

KEY WORDS: IMMATURE TOOTH APEX, ENDODONTIC TREATMENT, PERMANENT TEETH, ROOT CANAL SYSTEM.

\section{INTRODUCTION}

The endodontic treatment of permanent teeth with open apices and necrotic pulp is considered one of the most complex challenges for many clinicians. Usually, these teeth are associated with young people who develop early cavities, have a morphological anomaly or have suffered a dental trauma that prematurely halts root development (Flanagan, 2014) The cause of open apex formation in permanent teeth is due to a wide variety of factors such as pathological (external inflammatory root resorption) or iatrogenic (over-instrumentation) factors, that modify the mature apical lumen diameter (Plascencia et al., 2017). Various methods have been employed by

\section{ARTICLE INFORMATION}

*Corresponding Author: subash@saveetha.com

Received 29th July 2020 Accepted after revision 26th Sep 2020

Print ISSN: 0974-6455 Online ISSN: 2321-4007 CODEN: BBRCBA

Thomson Reuters ISI Web of Science Clarivate Analytics USA and Crossref Indexed Journal

\section{Clarivate
Analytics}

NAAS Journal Score 2020 (4.31) SJIF: 2020 (7.728)

A Society of Science and Nature Publication,

Bhopal India 2020. All rights reserved.

Online Contents Available at: http//www.bbrc.in/

Doi: http://dx.doi.org/10.21786/bbrc/13.8/112 different authors for the assessment for the growth of tooth development. Several authors have used different classification for the assessment of root development (Sapir and Shapira, 2008).

The most commonly used is the classification given by Cvek et al (4) who had arrived at a classification for root development by doing a retrospective study on 885 single rooted teeth. Cveks described the stages of tooth development in 5 stages, Stage 1: less than half the root length, Stage 2: half the root length, Stage 3: $2 / 3$ of the root length, Stage 4: Wide open apical foramen with almost complete root formation, Stage 5: Closed apical foramen formation with complete mature apex formation. While in Stage 5 the root formation is complete but the other stages such as Stage 1-3 have an open apex formation and cause a dilemma in the treatment protocol among various clinical practitioners.

The major dilemma is seen in conditions where the root development is classified into the first 3 stages due to the various treatment modalities available such

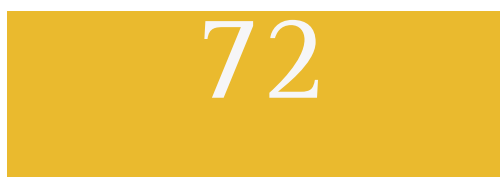


as apexification (Rafter, 2005; Sapir and Shapira, 2008) or regenerative endodontic procedure (Lee et al., 2015) depending on the various factors (Govindaraju, Neelakantan and Gutmann, 2017; Azeem and Sureshbabu, 2018; Jenarthanan and Subbarao, 2018; Manohar and Sharma, 2018; Nandakumar and Nasim, 2018; Teja, Ramesh and Priya, 2018; Janani and Sandhya, 2019; Khandelwal and Palanivelu, 2019; Malli Sureshbabu et al., 2019; Poorni, Srinivasan and Nivedhitha, 2019; Rajakeerthi and Ms, 2019; Rajendran et al., 2019; Ramarao and Sathyanarayanan, 2019; Siddique and Nivedhitha, 2019; Siddique et al., 2019; Siddique, Nivedhitha and Jacob, 2019).

\section{Definitions}

Regenerative endodontic procedures can be defined as biologically based procedures designed to replace a damaged structure, including dentin and root structure as well as cells of the pulp-dentin complex (Murray, Garcia-Godoy and Hargreaves, 2007). Apexification is a method to induce a calcified barrier in a root with an open apex or the continued apical development of an incompletely formed root in teeth with necrotic pulp (25) (AAE-2015)

\section{Considerations \\ Different factors are to be considered for the treatment of such cases \\ 1. Age \\ 2. Patient Cooperation \\ 3. Apex diameter \\ 4. Degree of infection in the canal \\ 5. Degree of root formation of the immature tooth}

Age: It is seen in various reports that the patient of a young age has a better success rate of regenerative endodontic procedure compared to older individuals. It was seen that ages of 8-16 years are the more ideal candidates for regenerative endodontic procedure depending on various clinical studies (Banchs and Trope, 2004; Araújo et al., 2017). Patient Cooperation: This is another major factor associated with the treatment selection for management of immature permanent tooth. One of the main disadvantages for revascularization procedure is the follow-recall period in which the patient requires to come in subsequent time intervals for evaluation

Apex Diameter: The width of the apex diameter plays an important role in the treatment selection criteria with literature showing that if the apex diameter is more than $1.1 \mathrm{~mm}$ then the treatment of choice is apexification

Degree of infection in the canal: Elimination of microbial organisms form the root canal system is one of the major criteria for the disinfection.

Degree of root formation of the immature tooth: Various authors (Kahler and Rossi-Fedele, 2016; Austah et al., 2018; Kim et al., 2018), have successfully done the treatment of the immature tooth with open apex but many of the authors have not taken in regard the degree of root formation of the tooth. Recently literature has shown that the degree of root formation also plays a role in the development of the immature permanent tooth with open apex.

Mechanism of Action of Root Formation: The major criteria for regenerative endodontic therapy are to release as many growth factors as possible which enables the physiological development of the root. These growth factors are present in the dentinal matrix. The most commonly seen growth factors are TGF- $\beta 1$, fibroblast growth factors 2 (FGF2) and platelet derived growth factors (PDGF) with each of the growth factors being specific in its function such as TGF- $\beta 1$, FGF2, VEGF and insulin-like growth factors stimulate cell proliferation, BMP and FGF2 promote dentinogenesis and PDGF and vascular endothelial growth factors (VEGF) controls angiogenesis. The combined effect of these growth factors enables the continuous development of the roots until the root formation is complete (30).

\section{Management of Tooth With Necrotic Pulp and Open Apex}

1. Pulp sensibility testing: The use of pulp sensibility testing gives the clinician invaluable information on the health status of the pulp. Various tests have been administered for the assessment such as cold test, Electric pulp testing, and Heat tests. Fuss et al (Fuss et al., 1986) in their in-vivo study had done an analysis in which they assessed the pulpal response and found dichlorodifluoromethane (DDM) to be much superior compared to CO2 snow. Levin et al (Levin, 2013)showed that the response had been similar to permanent tooth with mature apex in most of the case scenarios. The non vital tooth usually shows negative response due to failure to stimulate the nerve stimulus in the tooth.

2. Access opening: The access opening can be done using Endo access bur. One of the major factors to be considered for such case scenarios is the preparation of straight-line access from the coronal reference to the apex. Schroeder et al (Schroeder, Walton and Rivera, 2002)had done a study to evaluate the significance of straight line access and found that canals with a straight line access had shown a lesser deviation of working length when compared to curved canals This necessitates the significance of straight line access.

3. Working length determination: The working length should be kept $2 \mathrm{~mm}$ short of apex followed by which enlargement of the coronal orifice is done using Gates glidden drills. The orifice enlargement is done followed by cleaning and shaping of the canal is done using Hand instruments such as $\mathrm{K}$ - files up to the desired length.

4. Instrumentation: Growth factor and other cells are essential for the regeneration process could also be eliminated by instrumentation. Two types of cells are required to achieve a normal root development: odontoblasts and epithelial cells of Hertwig's epithelial root sheath (Zeichner-David et al., 2003). Another 
one of the factors to be considered is the apical area inflammation which secondary odontoblasts with vital stem cell preservation. For the regenerative endodontic procedure, minimal instrumentation has shown major success in the treatment of tooth because it has shown in various studies that minimal instrumentation better treatment outcome when compared to complete instrumentation due to studies showing that it does not interfere or degrade the SCAP cells present in the apical papilla region (Galler, 2016).

5. Disinfection of the Root Canal System: Disinfection of the root canal system is critical for the success of endodontic treatment procedure as this has a major effect on the prognosis of treatment. The presence of infection has many adverse effects which prevents regeneration, repair and stem cell activity. Chemical disinfection of the root canal system is not solely dependent on bactericidal and bacteriostatic properties of the agents as these irrigants and medicaments should not damage the survival and proliferative capacity of the patient's stem cells. It is recommended in guidelines that an irrigation regimen of 5.25\% sodium hypochlorite is recommended for 1 minute. A study done by Mohmmed et al (Mohmmed et al., 2017)had shown different results showing that even with the irrigation of 5.25\% sodium hypochlorite for 1 minute couldn't efficiently clear out the E. faecalis biofilm. Martins et al (Martin et al., 2014) have shown that fusage of $1.5 \%$ sodium hypochlorite had lesser effect on the SCAP cells when compared to $6 \%$ sodium hypochlorite used in their study. Another one factor to be considered is the biocompatibility issue for these commonly used irrigants which have shown to have cytotoxic potential to the cells. In order to counter this various other alternative irrigants have been used such as Noni juice and Aquatine EC. Further research should be done for seeing its significance in clinical scenarios.

In the case of apexification the irrigation protocol to be used is 5.25\% sodium hypochlorite and 17\% EDTA solution as a final irrigant (Shabahang, 2013). It is seen that tissue dissolving capacity of sodium hypochlorite varies depending on the concentration used the recommended protocol to be used is 5.25\% sodium hypochlorite and 17\% EDTA as final irrigation for cases with mature apex formation but chances of extrusion of these chemical agents is much higher for a tooth with immature apex. The clinician should take utmost care when using solutions for these types of case scenarios and care should be taken when doing these types of cases. One of the methods of reduction of apical extrusion is the use of EndoVac system which is a negative pressure system designed to enable the removal of the irrigant from the canal. This is supported by different studies. Gade et al (Gade et al., 2013) had shown the advantage of using an EndoVac system for the removal of apical extruded irrigants when compared to conventional needles or needles used with microcannula. chlorhexidine

6. Intracanal Medicaments: The use of intracanal medicaments is another factor to be considered for the disinfection of the root canal system. The ideal requirement of any intracanal medicament is its subsequent release of antimicrobial action for a long period of time when placed in the canal. The most recommended intracanal medication used is calcium hydroxide introduced by Herman in 1920. It is given by Siqueira et al (Siqueira and Lopes, 1999)that the mechanism of antimicrobial action of calcium hydroxide is by these 3 process; damage to the bacterial cytoplasmic membrane, protein denaturation and damage to the DNA. The use of a vehicle is one of the critical factors for the application of the calcium hydroxide in the intracanal space. For instance a viscous vehicle will remain in the canal for a longer period of time compared to a waterbased vehicle used (Mohammadi and Dummer, 2011).

Another most commonly used intracanal medicament is triple antibiotic paste (TAP) found by Banchs and Trope consisting of metronidazole, ciprofloxacin and minocycline. It was based on the concept of LSTR therapy which employs a combination of various antibacterial drugs for the disinfection of oral infectious lesions including dentinal, pulpal and periradicular lesions. It was found that the majority of the bacteria in the infected root canal dentin are obligate anaerobes for this reason metronidazole was taken as a first choice among the antibacterial drugs. The use of triple antibiotic paste has shown major success in the reduction of the microbial count in the infected root canal system and has shown that even in low concentration such as $1,0.1$ and .01 $\mathrm{mg} / \mathrm{ml}$ has the ability to eradicate Enterococcus faecalis colonies with less effect on the viability of stem cells.

It is also shown to have much better antibacterial potential to calcium hydroxide. One of the major adverse effects of use of TAP is the discolouration of the tooth when placed for extended periods with many case reports supporting the same. The reason being the presence of minocycline. In order to negate the use of double antibiotic paste is advised which consists of metronidazole and ciprofloxacin (Vijayaraghavan et al., 2012). One of recently introduced intracanal medicament used in endodontics is emdogain which is shown to have significantly higher antimicrobial effect and lesser deleterious effects the stem cell activity (Wang et al., 2018).

\section{Protocol To Be Followed For Necrotic Teeth With Open Apices \\ 1st Visit}

- Pre Evaluation of the case using clinical history and radiographic findings

- Access opening with EndoAccess Bur followed by which working length determination is done

- Cleaning and shaping of the root canal system with subsequent irrigation using $1.5 \%$ sodium hypochlorite $(20 \mathrm{ml})$ and saline irrigation $(40 \mathrm{ml})$.

- Final irrigation to be done using $2 \%$ Chlorhexidine gluconate $(5 \mathrm{ml})$ or $1 \%$ Alexidine Digluconate (5ml).

- Activation of the bisguanide based irrrigant (5ml) using Sonic or Ultrasonic activation 
- Placement of an intracanal medicament -Double Antibiotic Paste or Modified Triple Antibiotic paste/ Emdogain

\section{2nd Visit - After 1 week}

- Evaluation of the tooth - radiographic examination followed by pain assessment of the individual

- Irrigation of the canal using Saline to remove the medicament

- Copious Irrigation using $1.5 \%$ Sodium hypochlorite and final irrigation of 17\% EDTA (20ml, 5 mins) followed by which the canals are dried using paper points.

- $\quad$ During the irrigation procedure the patient should be asymptomatic completely with no debris coming from the canal.

- In the presence of any craze lines, fractured tooth the recommended protocol to be followed is apexification followed by Full Veneer Crown.

- In the presence of only discoloration with no fracture or minimal fracture requiring no additional treatment such as post endodontic restoration then the adviced protocol to be followed is revascularization. The selection of the treatment modality revascularization depends on various factors such as age of the patient which should be less than 25 years and cooperative patient.

- If the root length is more than 2/3rd using Cveks criteria evaluation is done on radiograph - the recommended treatment protocol is apexification.

- If the root length is less than 2/3rd using Cveks criteria radiographic evaluation is done -treatment protocol that can be followed is revascularization.

- Recall after a duration of 1 month, 3 months, 6 months, 1 year, 2 years, 5 years for follow-up

- CBCT Evaluation after a 1 year of the tooth of interest to evaluate the dentin thickness

\section{CONCLUSION}

The following practice guideline is effective for the treatment of immature teeth with open apex and is a major dilemma among all the dental practitioners. This guideline provide an show an effective way to the clinician for the management of immature open apex

\section{ACKNOWLEDGMENTS}

\section{None}

\section{Conflict of Interest: None}

\section{REFERENCES}

Araújo, P. R. de S. et al. (2017) 'Pulp Revascularization: A Literature Review', The Open Dentistry Journal, pp. 48-56. doi: 10.2174/1874210601711010048.

Austah, O. et al. (2018) 'Comprehensive Characterization of 2 Immature Teeth Treated with Regenerative Endodontic Procedures', Journal of Endodontics, pp. 1802-1811. doi: 10.1016/j.joen.2018.09.007.

Azeem, R. A. and Sureshbabu, N. M. (2018) 'Clinical performance of direct versus indirect composite restorations in posterior teeth: A systematic review', Journal of conservative dentistry: JCD, 21(1), pp. 2-9. Banchs, F. and Trope, M. (2004) 'Revascularization of Immature Permanent Teeth With Apical Periodontitis: New Treatment Protocol?', Journal of Endodontics, pp. 196-200. doi: 10.1097/00004770-200404000-00003.

Flanagan, T. A. (2014) 'What can cause the pulps of immature, permanent teeth with open apices to become necrotic and what treatment options are available for these teeth', Australian Endodontic Journal, pp. 95-100. doi: 10.1111/aej.12087.

Fuss, Z. et al. (1986) 'Assessment of reliability of electrical and thermal pulp testing agents', Journal of Endodontics, pp. 301-305. doi: 10.1016/s00992399(86)80112-1.

Gade, V. et al. (2013) 'Comparative evaluation of debris removal from root canal wall by using EndoVac and conventional needle irrigation: An in vitro study', Contemporary Clinical Dentistry, p. 432. doi: 10.4103/0976-237x.123019.

Galler, K. M. (2016) 'Clinical procedures for revitalization: current knowledge and considerations', International Endodontic Journal, pp. 926-936. doi: 10.1111/ iej.12606.

Govindaraju, L., Neelakantan, P. and Gutmann, J. L. (2017) 'Effect of root canal irrigating solutions on the compressive strength of tricalcium silicate cements', Clinical oral investigations, 21(2), pp. 567-571.

Janani, K. and Sandhya, R. (2019) 'A survey on skills for cone beam computed tomography interpretation among endodontists for endodontic treatment procedure', Indian journal of dental research: official publication of Indian Society for Dental Research, 30(6), pp. 834-838.

Jenarthanan, S. and Subbarao, C. (2018) 'Comparative evaluation of the efficacy of diclofenac sodium administered using different delivery routes in the management of endodontic pain: A randomized controlled clinical trial', Journal of conservative dentistry: JCD, 21(3), pp. 297-301.

Kahler, B. and Rossi-Fedele, G. (2016) 'A Review of Tooth Discoloration after Regenerative Endodontic Therapy', Journal of Endodontics, pp. 563-569. doi: 10.1016/j. joen.2015.12.022.

Khandelwal, A. and Palanivelu, A. (2019) 'Correlation Between Dental Caries And Salivary Albumin In Adult Population In Chennai: An In Vivo Study', Brazilian Dental Science, 22(2), pp. 228-233.

Kim, S. G. et al. (2018) 'Regenerative endodontics: a comprehensive review', International Endodontic Journal, pp. 1367-1388. doi: 10.1111/iej.12954.

Lee, B.-N. et al. (2015) 'A review of the regenerative endodontic treatment procedure', Restorative Dentistry \& Endodontics, p. 179. doi: 10.5395/rde.2015.40.3.179. 
Levin, L. G. (2013) 'Pulp and Periradicular Testing', Journal of Endodontics, pp. S13-S19. doi: 10.1016/j. joen.2012.11.047.

Malli Sureshbabu, N. et al. (2019) ‘Concentrated Growth Factors as an Ingenious Biomaterial in Regeneration of Bony Defects after Periapical Surgery: A Report of Two Cases', Case reports in dentistry, 2019, p. 7046203.

Manohar, M. P. and Sharma, S. (2018) 'A survey of the knowledge, attitude, and awareness about the principal choice of intracanal medicaments among the general dental practitioners and nonendodontic specialists', Indian journal of dental research: official publication of Indian Society for Dental Research, 29(6), pp. 716-720.

Martin, D. E. et al. (2014) 'Concentration-dependent effect of sodium hypochlorite on stem cells of apical papilla survival and differentiation', Journal of endodontia, 40(1), pp. 51-55.

Mohammadi, Z. and Dummer, P. M. H. (2011) 'Properties and applications of calcium hydroxide in endodontics and dental traumatology', International Endodontic Journal, pp. 697-730. doi: 10.1111/j.13652591.2011.01886.x.

Mohmmed, S. A. et al. (2017) 'The effect of sodium hypochlorite concentration and irrigation needle extension on biofilm removal from a simulated root canal model', Australian endodontic journal: the journal of the Australian Society of Endodontology Inc, 43(3), pp. 102-109.

Murray, P. E., Garcia-Godoy, F. and Hargreaves, K. M. (2007) 'Regenerative Endodontics: A Review of Current Status and a Call for Action', Journal of Endodontics, pp. 377-390. doi: 10.1016/j.joen.2006.09.013.

Nandakumar, M. and Nasim, I. (2018) 'Comparative evaluation of grape seed and cranberry extracts in preventing enamel erosion: An optical emission spectrometric analysis', Journal of conservative dentistry: JCD, 21(5), pp. 516-520.

Plascencia, H. et al. (2017) 'Management of permanent teeth with necrotic pulps and open apices according to the stage of root development', Journal of Clinical and Experimental Dentistry, pp. 0-0. doi: 10.4317/ jced.54287.

Poorni, S., Srinivasan, M. R. and Nivedhitha, M. S. (2019) 'Probiotic strains in caries prevention: A systematic review', Journal of conservative dentistry: JCD, 22(2), pp. 123-128.

Rafter, M. (2005) 'Apexification: a review', Dental Traumatology, pp. 1-8. doi: 10.1111/j.16009657.2004.00284.x.

Rajakeerthi, R. and Ms, N. (2019) 'Natural Product as the Storage medium for an avulsed tooth - A Systematic Review', Cumhuriyet Dental Journal, 22(2), pp. 249256.
Rajendran, R. et al. (2019) 'Comparative Evaluation of Remineralizing Potential of a Paste Containing Bioactive Glass and a Topical Cream Containing Casein Phosphopeptide-Amorphous Calcium Phosphate: An in Vitro Study', Pesquisa brasileira em odontopediatria e clinica integrada, 19(1), pp. 1-10.

Ramarao, S. and Sathyanarayanan, U. (2019) 'CRA Grid - A preliminary development and calibration of a paper-based objectivization of caries risk assessment in undergraduate dental education', Journal of conservative dentistry: JCD, 22(2), pp. 185-190.

Sapir, S. and Shapira, J. (2008) 'Decoronation for the management of an ankylosed young permanent tooth', Dental Traumatology, pp. 131-135. doi: 10.1111/j.16009657.2006.00506.x.

Schroeder, K. P., Walton, R. E. and Rivera, E. M. (2002) 'Straight line access and coronal flaring: effect on canal length', Journal of endodontia, 28(6), pp. 474-476.

Shabahang, S. (2013) 'Treatment Options: Apexogenesis and Apexification', Journal of Endodontics, pp. S26S29. doi: 10.1016/j.joen.2012.11.046.

Siddique, R. et al. (2019) 'Qualitative and quantitative analysis of precipitate formation following interaction of chlorhexidine with sodium hypochlorite, neem, and tulsi', Journal of conservative dentistry: JCD, 22(1), pp. 40-47.

Siddique, R. and Nivedhitha, M. S. (2019) 'Effectiveness of rotary and reciprocating systems on microbial reduction: A systematic review', Journal of conservative dentistry: JCD, 22(2), pp. 114-122.

Siddique, R., Nivedhitha, M. S. and Jacob, B. (2019) 'Quantitative analysis for detection of toxic elements in various irrigants, their combination (precipitate), and para-chloroaniline: An inductively coupled plasma mass spectrometry study', Journal of conservative dentistry: JCD, 22(4), pp. 344-350.

Siqueira, J. F. and Lopes, H. P. (1999) 'Mechanisms of antimicrobial activity of calcium hydroxide: a critical review', International Endodontic Journal, pp. 361-369. doi: 10.1046/j.1365-2591.1999.00275.x.

Teja, K. V., Ramesh, S. and Priya, V. (2018) 'Regulation of matrix metalloproteinase-3 gene expression in inflammation: A molecular study', Journal of conservative dentistry: JCD, 21(6), pp. 592-596.

Vijayaraghavan, R. et al. (2012) 'Triple antibiotic paste in root canal therapy', Journal of Pharmacy and Bioallied Sciences, p. 230. doi: 10.4103/0975-7406.100214.

Wang, H. H. et al. (2018) 'Application of Enamel Matrix Derivative (Emdogain) in Endodontic Therapy: A Comprehensive Literature Review', Journal of endodontia, 44(7), pp. 1066-1079.

Zeichner-David, M. et al. (2003) 'Role of Hertwig's epithelial root sheath cells in tooth root development', Developmental Dynamics, pp. 651-663. doi: 10.1002/ dvdy. 10404. 